\title{
BMJ Open Opt-out bloodborne virus screening: a cross-sectional observational study in an acute medical unit
}

\author{
Niamh Allen, ${ }^{1,2}$ Collette Faherty, ${ }^{3}$ Andre Davies, ${ }^{4}$ Anne Lyons, ${ }^{2}$ Margarent Scarry, ${ }^{2}$ \\ Mary Bohan Keane, ${ }^{5}$ Nicola Boyle, ${ }^{2}$ Sarah O'Connell, ${ }^{6}$ Eithne McCarthy, ${ }^{7}$ \\ Deirbhile Keady, ${ }^{7}$ Colm Bergin, ${ }^{8}$ John Lee, ${ }^{5}$ Catherine Fleming, ${ }^{2}$ David Gallagher, ${ }^{2,4}$ \\ Helen Tuite ${ }^{2}$
}

\begin{abstract}
To cite: Allen N, Faherty C, Davies A, et al. Optout bloodborne virus screening: a cross-sectional observational study in an acute medical unit. BMJ Open 2019;9:e022777. doi:10.1136/ bmjopen-2018-022777

- Prepublication history for this paper is available online. To view these files, please visit the journal online (http://dx.doi. org/10.1136/bmjopen-2018022777).
\end{abstract}

Received 20 March 2018 Revised 4 April 2019 Accepted 14 June 2019

Check for updates

(C) Author(s) (or their employer(s)) 2019. Re-use permitted under CC BY-NC. No commercial re-use. See rights and permissions. Published by BMJ.

For numbered affiliations see end of article.

Correspondence to

Dr Niamh Allen;

allen.niamh@gmail.com

\section{ABSTRACT}

Objective Recent treatment developments for HIV, hepatitis $\mathrm{C}$ virus (HCV) and hepatitis B virus (HBV) have greatly improved prognoses. Current screening practices are mainly risk based and are suboptimal. Improved efforts are critically needed to identify persons with these viruses. The aims of this study were to assess the feasibility of an opt-out bloodborne virus (BBV) screening programme in an acute medical unit (AMU) and to describe the prevalence of HIV, HBV and HCV in this population.

Design and setting This was a cross-sectional observational study in the AMU of a tertiary referral hospital in Galway, a city in the west of Ireland.

Participants 1936 patients entered the study; $54 \%$ were male, mean age was 53.1 years (SD 19.6). During the study period, all patients attending the AMU aged $\geqq 16$ years who were having bloods drawn and who had the ability to verbally consent for an additional blood sample met the inclusion criteria for the study.

Results Over 44 weeks, 1936/4793 (40.4\%) patients consented to BBV panel testing. Diagnosed prevalence rates for HIV, HBV and HCV were 0.5/1000, 2/1000 and $1.5 / 1000$, respectively. There was one HIV-positive result; the patient was already engaged in care. Four patients tested positive for HBV surface antigen; one new diagnosis, one previously lost to follow-up and two already engaged in care. Three patients had active HCV infection; two had been lost to follow-up and are now linked back into services.

Conclusion BBV testing uptake of $40.4 \%$ is higher than previous studies in AMU settings that used opt-in strategies, but lower than expected, possibly due to not incorporating testing into routine practice. The diagnosed prevalence of $\mathrm{HBV}$ is notable as little data currently exist about its prevalence in Ireland. These data are valuable in order to inform further prevention strategies for these infections in low-prevalence settings.

\section{INTRODUCTION}

Infection with HIV, hepatitis C virus (HCV) and hepatitis B virus (HBV) account for significant morbidity and mortality globally, including in Ireland; screening has both personal and public health benefits. ${ }^{1-3}$ All

\section{Strengths and limitations of this study}

To the best of our knowledge, this is the first opt-out bloodborne virus (BBV) screening study to be carried out in an acute medical unit (AMU).

- Routine opt-out screening for all three viruses was feasible for patients and staff and could help remove stigma associated with testing for these viruses.

- To ensure minimal disruption to the workflow in the AMU, no staff feedback, patient feedback or possible risk demographic data were collected.

- There is a possibility that this study does not reflect the true prevalence of these infections as patients with these infections may have opted out of BBV panel testing.

three viral infections can be diagnosed on serum samples, and for all three infections, treatment is available which leads to better patient outcomes and lower rates of onward transmission. ${ }^{45}$ Late diagnosis can lead to increased morbidity and mortality, increased use of resources and increased costs of care. ${ }^{12}$ Furthermore, these infections often occur in marginalised groups who are less likely to present for routine testing and therefore who are more likely to present late with advanced disease. ${ }^{36-8}$

\section{HIV}

Worldwide an estimated $0.8 \%(0.7 \%-0.9 \%)$ of adults aged 15-49 years are living with HIV, ${ }^{9}$ and in Europe there are between 30000 and 33000 new cases of HIV reported each year. ${ }^{10}$ Previous studies have estimated the diagnosed prevalence rates of HIV in Ireland (table 1) ${ }^{61011}$ To date in Ireland, 5253 people have been diagnosed with HIV, but it is estimated that, in keeping with statistics for the rest of Europe, about 15\% of HIV infections remain undiagnosed. ${ }^{12}{ }^{13}$ Approximately 90\% of those with diagnosed HIV infection in Ireland are on treatment, and $90 \%$ of these 


\begin{tabular}{|c|c|c|c|c|c|}
\hline & $\begin{array}{l}\text { Current screening } \\
\text { practice }\end{array}$ & $\begin{array}{l}\text { Recommended screening } \\
\text { practice }\end{array}$ & Prevalence & $\begin{array}{l}\text { Main transmission } \\
\text { modes }\end{array}$ & Population affected \\
\hline HIV & $\begin{array}{l}\text { Risk based } \\
\text { STI clinics } \\
\text { Antenatal screening } \\
\text { Blood donation } \\
\text { (opt-out) }\end{array}$ & $\begin{array}{l}\text { Universal in areas of high } \\
\text { prevalence }(>2 / 1000)^{19} \\
\text { Opt-out screening for } \\
\text { all patients attending for } \\
\text { healthcare aged } 13-64^{15}\end{array}$ & $\begin{array}{l}\text { Estimated } 1 / 1000^{11} \\
2.25 / 1000 \text { in Dublin ED } \\
\text { Estimated } 15 \% \text { of infections } \\
\text { undiagnosed }\end{array}$ & $\begin{array}{l}\text { Sexual } \\
\text { injection drug use }\end{array}$ & $\begin{array}{l}\text { MSM } \\
\text { PWID }\end{array}$ \\
\hline HBV & $\begin{array}{l}\text { Risk based } \\
\text { STI clinics } \\
\text { Antenatal screening } \\
\text { Blood donation }\end{array}$ & $\begin{array}{l}\text { Screening for all immigrants } \\
\text { coming from areas where HBV } \\
\text { prevalence }>2 \%^{32}\end{array}$ & $\begin{array}{l}<1 \% \\
\text { Ireland has one of the highest } \\
\text { rates of HBV and } \mathrm{HCV} \text { new } \\
\text { notifications in Europe }{ }^{30}\end{array}$ & $\begin{array}{l}\text { Vertical transmission } \\
\text { (occurring outside of } \\
\text { Ireland) }\end{array}$ & $\begin{array}{l}\text { Persons from } \\
\text { countries of high } \\
\text { endemnicity }^{7}\end{array}$ \\
\hline
\end{tabular}

BBV, bloodborne virus; ED, emergency department; HBV, hepatitis B virus; HCV, hepatitis C virus; MSM, men who have sex with men; PWID, people who inject drugs; STI, sexually transmitted infection.

patients are virally suppressed, ${ }^{10}$ suggesting that our main gap to achieving United Nations Programme on HIV/ AIDS (UNAIDS) 90/90/90 targets is around diagnosis. $^{13} 14$

Active case finding of undiagnosed HIV infection leads to better prognosis for individual patients and prevents the onward transmission of HIV by viraemic patients who are unaware of their HIV status. ${ }^{15}$ The Center for Disease Control (CDC) estimates that if everyone with HIV infection was diagnosed, there would be approximately one-third fewer new sexual HIV transmissions. ${ }^{15}$

The Strategic Timing of Antiretroviral Therapy (START) trial (August 2015) showed clinical benefits for patients who started treatment early in their disease course, which requires diagnosing infection before it presents clinically, ${ }^{16}$ and a recommendation for earlier treatment initiation has been incorporated into international guidelines. However, with our current HIV testing methods, patients are continuing to present late (defined as a CD 4 cell count $<350$ ). Forty-five per cent of those presenting with HIV in Ireland in 2015 presented late. ${ }^{3}$ Previous studies have shown that healthcare workers are also a barrier to testing. Testing has previously been associated with a laboured process of pretest counselling and written consent; many providers are unaware of the changes in testing guidelines, and importantly are unaware of the lack of need for written consent or extensive pretest counselling. ${ }^{151718}$

Current recommendations call for doctors to offer people HIV tests if they are at high risk of infection, ${ }^{19}$ but many healthcare providers do not make this assessment. Furthermore, by adopting this targeted testing approach, patients with high-risk behaviours may feel stigmatised by being singled out for HIV testing. Opt-out testing among pregnant women has already proven to be highly effective in preventing mother to child transmission of HIV by picking up unsuspected cases of HIV. ${ }^{20-22}$ CDC and UK National Guidelines both recommend opt-out HIV testing in patients presenting to healthcare services, but this strategy has not yet been widely implemented (table 1). ${ }^{15} 19$

\section{Hepatitis C virus}

The prevalence of HCV in Ireland is estimated at $0.5 \%-$ $1.2 \%$ (table 1 ) ${ }^{23}$ It is estimated that there are between 20100 and 42000 people with current infection in Ireland, and that up to $60 \%$ of these infections remain undiagnosed. ${ }^{24-28}$ Injection drug use is the most common risk factor associated with HCV acquisition in Ireland $(80 \%)$, followed by possible sexual exposure $(5 \%)$, receipt of blood or blood products $(4 \%)$, vertical transmission $(2 \%)$ and tattooing or body piercing $(1 \%) \cdot{ }^{24}$ Of note, there have been an increase in sexually transmitted HCV infections nationally in men who have sex with men from 4 in 2014 to 29 in $2016 .{ }^{23}$

Chronic undiagnosed HCV infection can lead to liver cirrhosis, hepatocellular carcinoma and death. ${ }^{23}$ The recent advances in treatment with oral, well-tolerated shorter course curative treatment with direct-acting antivirals (DAAs) for HCV have resulted in cure rates of $>90 \%$ in those treated. ${ }^{23}$ The Health Service Executive (HSE) National Hepatitis C Strategy 2011-2014 made recommendations across four key areas, which included expanded screening and treatment, after the recent availability of DAAs for HCV in Ireland in $2014 .^{24}$

\section{Hepatitis B virus}

While Ireland has a low HBV prevalence (thought to be $<1 \%$ ), from 2002 to 2008 there were a large number of new notifications in persons from areas of high endemicity, such as central Asian republics, South East Asia and sub-Saharan Africa ( $>8 \%$ prevalence) (table 1). ${ }^{78}$ The overall prevalence of HBV in the EU/EEA is low at $0.9 \%$ (range $0.1 \%-4.4 \%$ ). ${ }^{29}{ }^{30}$ According to the European Centre for Diseases Control data, Ireland still has one of the highest rates of HBV and HCV new notifications in Europe. ${ }^{30}$ Eighty per cent of notifications of chronic HBV 
in Ireland in 2013 were in persons from a country of high HBV prevalence or in persons with asylum seeker status. ${ }^{7}$

HBV infection can be controlled with antiviral medication, preventing complications related to liver failure. Onward transmission of HBV occurs more frequently than other BBVs but can be prevented by viral suppression through treatment in infected individuals and through vaccination of close contacts. ${ }^{7}$ The US CDC guidelines recommend HBV testing in those with exposure risk factors. ${ }^{31}$ The 2015 Health Protection Surveillance Centre guidelines recommend screening all immigrants who are coming from countries where prevalence of $\mathrm{HBV}$ is $>2 \%{ }^{32}$

\section{Diagnosis and screening}

No widespread screening programme is in place for HIV, $\mathrm{HCV}$ and HBV. Current screening practices for HIV and HBV in Ireland are mostly risk based, although CDC and UK guidelines call for opt-out screening in certain circumstances, for example, blood donation (table 1). ${ }^{15} 19 \mathrm{~A}$ recent study in Dublin showed high feasibility and acceptability of opt-out BBV screening in the emergency department (ED) of a tertiary referral hospital, with a cumulative uptake rate of $50.1 \%{ }^{6}$ Based on this, the study protocol has become routine practice in this ED, with ongoing opt-out BBV screening. A recent study in primary care centres in Dublin also showed high acceptability rate, with $89.5 \%$ uptake on opt-out BBV screening. ${ }^{33}$

The aims of this study were to assess the feasibility of an opt-out BBV screening programme in an acute medical unit (AMU) of a tertiary referral hospital in Galway, a city in the west of Ireland, and to describe the prevalence of HIV, HBV and HCV in this population. This study is, to our knowledge, the first to assess the feasibility of an opt-out screening approach for BBVs in an AMU in a low diagnosed prevalence area for BBVs. It is also the first to describe the prevalence of HIV, HBV and HCV in an AMU.

\section{METHODS}

This was a cross-sectional observational study conducted in the AMU of Galway University Hospital in the city of Galway, Ireland. The study involved collaboration between the AMU and the departments of Infectious Diseases, Microbiology, Virology and Hepatology.

Patients are referred to the AMU from the ED, or directly from general practitioners. All patients are medically stable. At registration, each patient was given a patient information leaflet by the administration staff to review and ask any further questions about the study. At least 20 min later, and with verbal consent, blood was drawn by nursing staff. Each clinical proforma used for routine clinical care was stamped with a reminder for the provider to ask the patient about consent to have bloods drawn for the study. In line with international guidelines for HIV testing and with local ethical approval, verbal consent was deemed sufficient for all three BBVs. ${ }^{15}{ }^{19} \mathrm{~A}$ streamlined process was developed by the microbiology/ virology team to manage the testing for all three viruses within a service which provides over 5000 new patient consultations per year. The study duration and sample size were determined by funding available. Patients did not receive any reimbursement for their inclusion in the study.

All samples were tested routinely, using the Abbott HBsAg Qualitative II, Abbott anti-HCV and Abbott HIV $\mathrm{Ag} / \mathrm{Ab}$ Combo assays. Results were processed in the on-site microbiology laboratory. Positive results were reported by phone to the study team as per routine clinical care. Results were managed on a "no news is good news' policy, with a dedicated phone line for patients to ring if they wanted to follow-up results or had any questions relating to the study.

Inclusion criteria were patients presenting new to the AMU who were aged 16 years or older and were having bloods drawn for any reason and who had capacity to consent to inclusion in the study. Targets for uptake of screening were set at $50 \%$ of patients accepting to participate in the study for the first 2 months, and $80 \%$ from month 3 onwards, based on the Dublin ED study targets and results. ${ }^{6}$ Linkage to care was coordinated by the study team where appropriate. Data analysis was primarily descriptive and was done using SPSS V.24. Prevalence rates for HIV, HCV and HBV infections were described and the feasibility of the study was assessed by the uptake of BBV testing.

\section{Patient and public involvement}

Neither patients nor public were involved in the development of the research question or the design of the study. Patients were recruited to the study as described in inclusion criteria above. Patients were not involved in the conduct of the study. Individual patient results were available to each patient via a phone line. Wider dissemination of the results of the study will be available via publication of this study.

\section{RESULTS}

From 18 January to 21 November 2016, 1936/4793 (40.4\%) patients were assessed for medical care in the department consented to BBV panel testing. A total of 1941 samples were each tested for HIV, HBV and HCV (five duplicate samples). Fifty-four per cent of the patients were male and their mean age was 53.1 years (SD 19.6) (figure 1). The diagnosed prevalence of HIV was $0.5 / 1000$. There was one HIV-positive result; this patient was previously diagnosed and engaged in care. The diagnosed prevalence of $\mathrm{HBV}$ was 2/1000. Four patients tested positive for HBV surface antigen; one new diagnosis, one previously lost to follow-up and now linked back into care and two already engaged in specialist care. One patient testing positive for HBV was $>65$ years of age. This patient came from a high-endemic area for HBV. The diagnosed prevalence of HCV was 1.5/1000. Six patients were HCV 


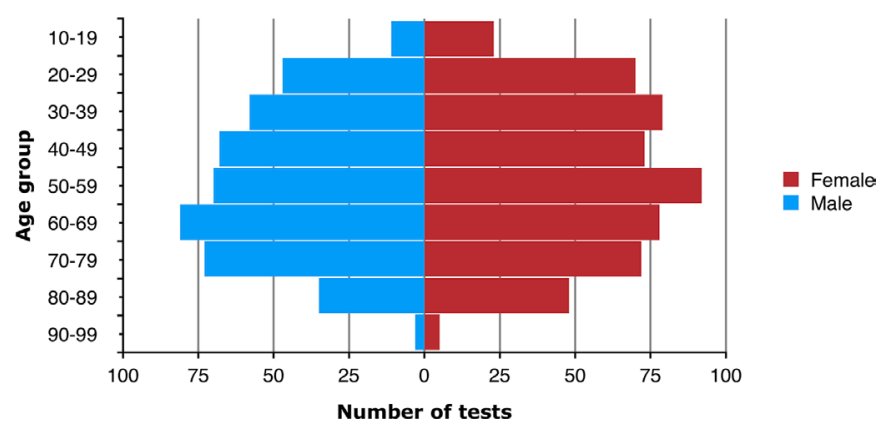

Figure 1 Demographics of patients testing for bloodborne virus in acute medical unit.

antibody $(\mathrm{Ab})$ positive. Three patients had active HCV infection; two had been lost to follow-up and are now linked back into services, the third was already engaged in care. Of the other three patients that were found to have evidence of HCV Ab positivity, only one declined follow-up bloods to assess for active infection; they had a prior documented undetectable viral load. Fifty per cent $(3 / 6)$ of the patients who tested positive for HCV Ab were $>65$ years of age.

The overall uptake of BBV screening over the course of the study was $40.4 \%$ (figure 2). The decline in testing from week 20 to week 23 reflects the unexpected relocation of the AMU department to a different section of the hospital. After this relocation, there was a further educational drive around testing; however, there was also a tail-off in testing towards the end of the study which affected the overall uptake (figure 2). One patient changed his/her mind about being included in the study, having initially agreed. There were no issues reported by patients to the study team either in person or via the dedicated phone line regarding the opt-out screening process.

\section{DISCUSSION}

The results of our study suggest that an AMU BBV screening programme is feasible. The percentage uptake of $40.4 \%$ is higher than previous studies in AMU settings

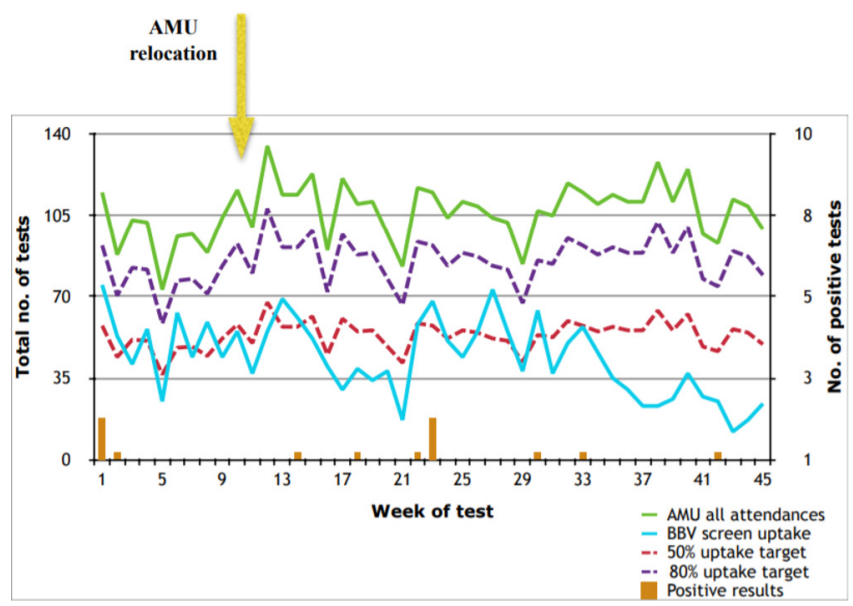

Figure 2 Bloodborne virus (BBV) screening uptake and results over study period. AMU, acute medical unit. that used opt-in strategies $(6 \%-22 \%) .{ }^{34}$ This uptake was calculated based on the assumption that all patients attending the AMU had bloods drawn and therefore were eligible for the study. There may have been some patients who did not have bloods done, in which case this uptake would be a slight underestimate. However, the uptake of testing was lower than expected, and lower than the cumulative $50.1 \%$ uptake achieved in an ED setting in Dublin, the capital city of Ireland, which has a higher volume of patients, including more critically unwell patients. ${ }^{6}$ It was also significantly lower than the uptake of $89.5 \%$ achieved in a study conducted across four urban primary care sites in Dublin. ${ }^{33}$ This was a research study and we believe that the uptake in our study was affected by not incorporating testing into routine clinical care. The significantly lower uptake in the AMU and ED studies compared with the $89 \%$ uptake achieved in the primary care setting may reflect the difference between care by a single provider in the community versus a larger team of providers in an ED or AMU setting (table 2).

The overall diagnosed prevalence rate of HIV of $0.5 / 1000$ was lower than previously reported..$^{10}{ }^{11}$ This likely reflects the possibility that patients triaged to AMU are not fully representative of the local population, tending to be older and often having more medical comorbidities. A similar study in the ED would be needed to ascertain the true prevalence of BBVs in the local population presenting to the hospital.

This prevalence of $0.5 / 1000$ does not meet the 2/1000 suggested in the British recommendations for opt-out testing for HIV. ${ }^{15}$ However, the study is still in line with WHO guidelines released as early as 2006 that recommend all patients presenting to healthcare between the ages of 13 and 64 should be tested at least once for HIV. ${ }^{15}$ Furthermore, modelling in the USA suggests that routine screening for HIV infections is cost-effective and comparable to costs of other routinely offered screening where the prevalence of HIV exceeds $0.5 / 1000 .^{35}$

The diagnosed prevalence of $\mathrm{HBV}$ of 2/1000 is notable as little data currently exist around HBV prevalence in Ireland. The urban ED study found a HBV prevalence rate of 5/1000 and the urban primary care setting showed a similar prevalence to ours of $2 / 1000^{30}$ (table 2). From a public health perspective, these data are valuable in order to inform further screening and prevention strategies for these infections in a low-prevalence setting. Understanding of rates of BBVs in different areas, and the patient demographics, is imperative when planning screening systems. In our case, all patients with $\mathrm{HBV}$ were from areas of high endemicity for HBV and therefore a risk-based screening programme should capture these infections.

We found a low HCV diagnosed prevalence rate of $1.5 / 1000$, compared with 50/1000 in the Dublin ED setting. ${ }^{6}$ This was expected in light of the reduced risk factors in our catchment area compared with Dublin, the most notable of these is the low prevalence of people who inject drugs (PWID) in the local community. Despite this, 
Table 2 Uptake rates and bloodborne virus prevalence rates across three study sites: urban primary care, urban emergency department and low-prevalence acute medicine unit

\begin{tabular}{llccc}
\hline & Uptake & HIV prevalence (/1000) & HBV prevalence (/1000) & HCV prevalence (/1000) \\
\hline Primary care & $89.5 \%$ & 0 & 2 & 2 \\
Emergency department & $50.1 \%$ & 11 & 50.5 & 5 \\
Acute medicine unit & $40.4 \%$ & 0.5 & 2 & 1.5 \\
\hline
\end{tabular}

HBV, hepatitis B virus; HCV, hepatitis C virus.

our prevalence results are in keeping with the estimated overall prevalence of HCV in Ireland, which is $0.5 \%-1.2 \%$, and are only slightly lower than the prevalence of 2/1000 found in the urban primary care setting ${ }^{33}$ (table 2 ). As for $\mathrm{HBV}$, little published data existed prior to this study about prevalence rates of HCV in our low-prevalence population, so these data are also valuable in informing further screening practices.

We feel that healthcare worker-associated barriers also contributed to our uptake being lower than expected, and lower than the uptake in the primary care study. This could be improved by education of healthcare practitioners about the lack of need for extensive pretest counselling and written consent, and by incorporating testing into routine care. Moreover, in areas of low prevalence targeted testing may be more difficult to achieve as people may not disclose their risk factors to their doctor. We believe that this study helped awareness about BBVs in the AMU and we feel that opt-out testing removed the stigma associated with BBV testing for both patient and the provider, as has been described previously. ${ }^{36}$

Notably $3 / 6(50 \%)$ of the patients who tested positive for HCV Ab in our study were over 65 years of age and would not have met routine screening criteria based on WHO guidelines. ${ }^{15}$ One 69-year-old man was unaware of having previously been infected and clearing HCV, and did not have any risk factors that would have been picked up by targeted testing. One patient testing positive for $\mathrm{HBV}$ was $>65$ years of age. This patient came from a high-endemic area and could have been picked up if targeted screening was systematically in place for patients coming from areas of high endemicity; however, this is not currently the case. Ireland also has an ageing HIV population and older patients may be less likely to be picked up with current screening practices. ${ }^{11}$

Our study had a number of limitations. In designing the study, a decision was made about the importance of a streamlined consent process; the study needed to fit in with routine work activities. Due to this, we could not collect any patient feedback or comparative data between patients who did and did not participate in the study. The study design of including all adults attending the AMU aimed to eliminate any bias in patients being included in the study. However, there is the chance that those who were in fact at high risk for BBV (particularly HIV and HCV) may have declined screening, and therefore our study may have underestimated prevalence. Another limitation is that a small number of patients may not have had bloods drawn, in which case the uptake would be underestimated. Risk demography was not collected and was difficult to ascertain retrospectively but this limitation is similar in opt-in studies. An unexpected challenge was the relocation of the AMU during the study, which was not foreseen and which impacted all activities, including this study, as seen by the decline in uptake from week 20 to week 23.

\section{CONCLUSION}

The results of this study suggest that opt-out BBV screening is feasible in an acute medical assessment unit setting, in an area of low prevalence for BBVs. The method of opt-out testing removes the stigma of BBV testing for both the patient and the provider. ${ }^{36}$

The percentage uptake of $40.4 \%$ is higher than previous studies in AMU settings that used opt-in strategies. ${ }^{11}$ However, the uptake of testing was lower than expected, and lower than that which was achieved in an urban ED setting ${ }^{6}$; this was a research study and we believe the uptake was affected by not incorporating testing into routine clinical care. The study has added valuable information on prevalence of BBVs in the study population. The diagnosed prevalence of $\mathrm{HBV}$ is most notable as little data currently exist about its prevalence in Ireland. The results suggest that a widespread AMU BBV screening programme throughout Ireland may be feasible. Modelling studies have been done to try to assess the cost-effectiveness of screening for HIV in high-prevalence settings, ${ }^{35}$ but to the best of our knowledge, there is no published data on cost-effectiveness of simultaneous BBV screening either inside or outside of Ireland. Further research is required to determine the cost-effectiveness of such a strategy and to evaluate the incidence and prevalence of BBVs in other catchment areas and healthcare settings.

\section{Author affiliations}

${ }^{1}$ Infectious Diseases, St James' Hospital, Dublin, Ireland ${ }^{2}$ Infectious Diseases, Galway University Hospitals, Galway, Ireland ${ }^{3}$ Microbiolgy/ Virology, Galway University Hospitals, Galway, Ireland ${ }^{4}$ Acute Medicine Unit, Galway University Hospitals, Galway, Ireland ${ }^{5}$ Hepatology, Galway University Hospitals, Galway, Ireland

${ }^{6}$ Infectious Disease, University Hospital Limerick, Dooradoyle, Ireland

${ }^{7}$ Microbiology, Galway University Hospitals, Galway, Ireland 
${ }^{8}$ Department of Genitourinary and Infectious Diseases, St. James's Hospital, Dublin, Ireland

Contributors $\mathrm{HT}, \mathrm{DG}, \mathrm{CB}$ and $\mathrm{SOC}$ designed the study protocol. $\mathrm{HT}$ and $\mathrm{DG}$ gained ethical approval for the study. NA, CF, AD, AL, MS, MBK and NB participated in the data collection. NA, AL, MS, MBK, NB, JL and CF ensured patients were linked to appropriate clinical care where required. CF, EMC and DK supervised the processing of laboratory samples and collated the laboratory data. NA, HT and DG analysed and interpreted the collated data. NA wrote the manuscript and all the authors reviewed the manuscript prior to publication.

Funding This study was funded by an unrestricted research grant from Merck Sharp and Dohme. They had no involvement in the interpretation of data and the writing of the manuscript.

Competing interests None declared.

Patient consent for publication Not required.

Ethics approval Ethical approval was sought and was granted by the Ethical Review Board of Galway University Hospital, with the main condition that patients should be allowed 20 min to decide on participation to ensure adequate time to read the patient information leaflet which outlined the study details.

Provenance and peer review Not commissioned; externally peer reviewed.

Data sharing statement All collected data have been described in the published manuscript.

Open access This is an open access article distributed in accordance with the Creative Commons Attribution Non Commercial (CC BY-NC 4.0) license, which permits others to distribute, remix, adapt, build upon this work non-commercially, and license their derivative works on different terms, provided the original work is properly cited, appropriate credit is given, any changes made indicated, and the use is non-commercial. See: http://creativecommons.org/licenses/by-nc/4.0/.

\section{REFERENCES}

1. World Health Organisation. Fact sheet no: 360 HIV/ AIDSS. 2015 www.who.int/mediacentre/factsheets/fs360/en (Accessed Mar 2019).

2. El Khoury AC, Klimack WK, Wallace C, et al. Economic burden of hepatitis C-associated diseases in the United States. J Viral Hepat 2012;19:153-60.

3. Health Protection Surveillance Centre. HIV in Ireland 2016 report. http://www.hpsc.ie/a-z/hivstis/hivandaids (Accessed Nov 2018).

4. The Lancet Hiv. $U=U$ taking off in 2017. Lancet HIV 2017;4:e475.

5. Cohen MS, Chen YQ, McCauley M, et al. Antiretroviral therapy for the prevention of HIV-1 transmission. N Engl J Med 2016;375:830-9.

6. O'Connell S, Lillis D, Cotter A, et al. Opt-out panel testing for HIV, Hepatitis B and Hepatitis C in an urban emergency department: a pilot study. PLoS One 2016;11:e0150546.

7. Health Protection Surveillance Centre (HPSC). Hepatitis B report 2015. http://www.hpsc.ie/a-z/hepatitis/hepatitisb/hepatitisbreports/ hepatitisannualreports/ (Accessed Nov 2018).

8. Franco E, Bagnato B, Marino MG, et al. Hepatitis B: epidemiology and prevention in developing countries. World $\mathrm{J}$ Hepatol 2012;4:74-80.

9. WHO. Global health observatory Data HIV/AIDS. http://www.who.int/ gho/hiv/en/ (Accessed Mar 2019).

10. ECDC. HIV and AIDs annual epidemiological report. 2016 https://ecdc.europa.eu/en/publications-data/hivaids-annualepidemiological-report-2016-2014-data (Accessed Nov 2018).

11. Tuite $\mathrm{H}$, Horgan M, Mallon PW, et al. Patients accessing ambulatory care for HIV-infection: epidemiology and prevalence assessment. Ir Med J 2015;108:199-202.

12. Public Health England. National HIV testing week report. 2013 https://www.gov.uk/government/news/phe-supporting-national-hivtesting-week (Accessed Mar 2019).

13. ECDC. Special report; continuum of HIV care. $2017 \mathrm{https} / / / \mathrm{ecdc}$. europa.eu/sites/portal/files/documents/Continuum-of-HIV-care-2017. pdf (Accessed Mar 2019).
14. UNAIDS. 90/90/90 - An Ambitious Treatment Target to help end the AIDS epidemic. http://www.unaids.org/sites/default/files/media asset/90-90-90_en.pdf (Accessed Mar 2019).

15. CDC. Morbidity and mortality weekly report, August 11th, 2006. https://www.cdc.gov/mmwr/index2017.html (Accessed Mar 2019).

16. Lundgren JD, Babiker AG, Gordin F, et al. Initiation of antiretroviral therapy in early asymptomatic HIV infection. N Engl J Med 2015;373:795-807.

17. Wilson JM, Jungner G. Principles and practice of screening for disease. Geneva, Switzerland: World Health Organization, 1968.

18. Tuite $\mathrm{H}$, Lynam A, Ferris $\mathrm{H}$, et al. Universal HIV testing by junior doctors: challenges in its implementation. HIV Medicine 2012;13:63.

19. British HIV Association (BHIVA). UK National guidelines for HIV testing, 2008. https://www.bhiva.org/HIV-testing-guidelines (accessed March 2018)

20. Barbacci MB, Dalabetta GA, Repke JT, et al. Human immunodeficiency virus infection in women attending an inner-city prenatal clinic: ineffectiveness of targeted screening. Sex Transm Dis 1990;17:122-6.

21. Fehrs LJ, Hill D, Kerndt PR, et al. Targeted HIV screening at a Los Angeles prenatal/family planning health center. Am J Public Health 1991;81:619-22.

22. Lindsay MK, Adefris W, Peterson HB, et al. Determinants of acceptance of routine voluntary human immunodeficiency virus testing in an inner-city prenatal population. Obstet Gynecol 1991;78:678-90.

23. Health Protection Surveillance Centre. HCV in Ireland 2016 Report. http://www.hpsc.ie/a-z/hepatitis/hepatitisc/hepatitiscreports/hepatiti sannualreports/ (Accessed Nov 2018).

24. Hepatitis C Screening. National clinical guideline. $2017 \mathrm{https}: / /$ health gov.ie/wp-content/uploads/2017/08/HepC-NCG-15_Summary_v8. pdf

25. Razavi $\mathrm{H}$, Robbins $\mathrm{S}$, Zeuzem S, et al. Hepatitis $\mathrm{C}$ virus prevalence and level of intervention required to achieve the WHO targets for elimination in the European Union by 2030: a modelling study. Lancet Gastroenterol Hepatol 2017;2:325-36.

26. Thornton L, Murphy N, Jones L, et al. Determination of the burden of hepatitis $\mathrm{C}$ virus infection in Ireland. Epidemiol Infect 2012;140:1461-8.

27. ICORN. Strategic plan 2014-2018. https://www.icorn.org/sites/ default/files/mediaroom/icorn_strategic_plan_2014-2018.pdf

28. Health Service Executive. Primary care reimbursement services 2013. https://www.hse.ie/eng/staff/pcrs/pcrs-publications/pcrsstatistical-analyis-of-claims-and-payments-2013.pdf (Accessed Mar 2019).

29. Hofstraat SHI, Falla AM, Duffell EF, et al. Current prevalence of chronic hepatitis $B$ and $C$ virus infection in the general population, blood donors and pregnant women in the EU/EEA: a systematic review. Epidemiol Infect 2017;145:2873-85.

30. European Centre for Disease Control (ECDC). Annual epidemiological report 2014 - sexually transmitted infections including HIV and blood-borne viruses. https://ecdc.europa.eu/sites/portal/files/media/ en/publications/Publications/sexually-transmited-infections-HIVAIDS-blood-borne-annual-epi-report-2014.pdf (Accessed Mar 2019).

31. Central for Disease Control. Recommendations for routine testing and follow-up for chronic hepatitis B Virus (HBV) Infection. https:// www.cdc.gov/hepatitis/hbv/PDFs/ChronicHepBTestingFlwUp.pdf (Accessed Mar 2019).

32. HPSE. Infectious disease assessment for migrants 2015. https:// www.hpsc.ie/a-z/specificpopulations/migrants/guidance/File,14742, en.pdf (Accessed Mar 2019).

33. O'Kelly M, Byrne D, Naughten E, et al. Opt-out testing for bloodborne viruses in primary care: a multicentre, prospective study. $\mathrm{Br} \mathrm{J}$ Gen Pract 2016;66:e392-6.

34. Palfreeman A, Nyatsanza F, Farn $\mathrm{H}$, et al. HIV testing for acute medical admissions: evaluation of a pilot study in Leicester, England. Sex Transm Infect 2013;89:308-10.

35. Sanders GD, Bayoumi AM, Sundaram V, et al. Cost-effectiveness of screening for HIV in the era of highly active antiretroviral therapy. $N$ Engl J Med 2005;352:570-85.

36. Young SD, Monin B, Owens D. Opt-out testing for stigmatized diseases: a social psychological approach to understanding the potential effect of recommendations for routine HIV testing. Health Psychol 2009;28:675-81. 